\title{
The disruption of the care chain: why do Lithuanian migrant home care workers return to their home country?
}

\author{
Liat Ayalon ${ }^{1 *}$ (D) and Gražina Rapolienè ${ }^{2}$ (D) \\ ${ }^{1}$ Louis and Gabi Weisfeld School of Social Work, Ramat Gan, Israel and ${ }^{2}$ Lithuanian Social Research \\ Centre, Vilnius, Lithuania \\ ${ }^{\star}$ Corresponding author. Email: liat.ayalon@biu.ac.il
}

(Accepted 22 September 2021)

\begin{abstract}
This study examined reasons for return migration among Lithuanian migrant home care workers who provided care to older adults abroad. In total, 13 interviews were conducted with a diverse sample of returnees. Using constant comparison, three major themes were identified. The first theme described the undocumented nature of the job as a reason to return. The emotional consequences of the job as well as its physically demanding aspects also were portrayed. The third theme addressed the increased awareness to possible losses and care needs brought by the job. Our findings stress the importance of the job characteristics of the worker as a push factor that results in the return of migrant workers to their home. The importance of the documentation status of the job and its precarious nature are discussed.
\end{abstract}

Keywords: migration; globalisation; migrant; domestic; care work; home care

\section{Introduction}

The past century has seen a dramatic flux in migration, as there are currently about 272 million migrants worldwide (United Nations International Organization for Migration, 2020). The non-linear features of immigration are of particular relevance (Olesen, 2002); some immigrants may move to more than one country, thus becoming transnational migrants, while others may adopt a circular pattern, going back and forth between the host country and the sending country. Yet others, may return to their home country, even after a very long period of stay in the host country. The present study is focused on the latter form of return migration to one's home country from the viewpoint of Lithuanian migrant home care workers who returned to Lithuania.

Lithuania is considered a sending country. Since the 1990s, it has experienced several waves of emigration (Thaut, 2009). The first wave occurred in early 1990, 
following the collapse of the former Soviet Union. This wave was characterised primarily by skilled men, who ended up pursuing undocumented jobs for which they were over-qualified. The second wave occurred in 2004, once Lithuania entered the European Union (EU) (Thaut, 2009). This migration wave was characterised by Lithuanians moving back and forth between higher-income European countries. In total, between 1990 and 2011, 728,700 people have emigrated from Lithuania, amounting to 20 per cent of the Lithuanian population in 1990 (Sipavičiene and Stankūnienè, 2013). As such, Lithuania is considered one of the most rapidly depopulating countries in the world, with an expected decline of 17 per cent of its population (Birka, 2019). Although statistics are unclear, it is estimated that following the financial crisis in 2008, Lithuanian migrants returned home, as the host countries were badly affected financially (Zaiceva and Zimmermann, 2016). However, return migration to Lithuania is considered low, estimated at 6,500 people per year (United Nations International Organization for Migration, 2011).

\section{Why do migrants return to their home country?}

Fairly simplistic explanations to account for the return of migrants to their home country classify the reasons for return as success versus failure (Wang and Fan, 2006). There are those who succeeded and achieved the status and/or obtained resources they had aspired to and, thus, return to their home country after achieving their goals. Alternatively, one may hypothesise that those who return to their home country are the ones who have failed to find a proper job or good education and were pushed away from the job market in the host country.

Support for these competing explanations can be found in past research. On the one hand, research has shown that many times, the return of migrants to their homes results in brain gain (Barcevičius, 2016). Migrants who are more educated than the general population, have more financial resources, and are more likely to innovate and contribute to the economy are the ones who return even after many years in the host country. These migrants might have left for a particular reason, to pursue a new job abroad or to obtain higher education. When they return they benefit their home country by bringing in an added value acquired during their stay in the host country (Labanauskas, 2019; Hagan and Thomas Wassink, 2020).

Return migration may also be portrayed as a failure. Past research has shown that when a financial crisis occurs, migrants are the first to get hurt (Bastia, 2011). They are the first to lose their jobs and become unemployed. Thus, it is migrants who suffer the most under unstable conditions. These migrants might return to their home countries as they have failed to secure a job in the host country (Zaiceva and Zimmermann, 2016).

Nonetheless, the reasons for returning to one's home country are more complex than a simple classification into success versus failure. Other plausible explanations have been offered, arguing that like the reasons to migrate, the reasons to return to one's home country are multifaceted, influenced by a variety of causes. A lifecourse perspective suggests that the lives of people and generations are interlinked (Stoller and Longino, 2001). Using this perspective, research has shown that migrants may return to their home country to take care of their loved ones who stayed behind. If, 
on the other hand, one's children live in the host country, it is highly likely that the migrant will stay there as well and will not return to his or her home country (Stoller and Longino, 2001; Cela, 2017).

Migration and return migration are gendered in nature (Girma, 2017; Preston and Grimes, 2019). The gender of the migrant plays a role not only in the personal decision to return to one's home country, but also at the structural-policy level. Specifically, past research has shown that not only are the work opportunities of men and women different, but so are the opportunities to work abroad legally. Whereas professional jobs, traditionally pursued by men, are more likely to result in a documented status overseas, care work, traditionally pursued by women and performed behind closed doors, is less likely to be documented (Kofman, 2013).

The exact lifestage may also play a role. Retirement represents an opportunity to return to one's home country. If the reasons for immigration were mainly financial, once employment is no longer an issue, the migrant might return to her or his home country. This stresses the importance of cultural and social ties, which may connect the migrant to her or his home country even years after migration (Klinthäll, 2006).

The characteristics of return migrants also have been explored. Specifically, professionals who returned to their home country are characterised as innovators (Klagge and Klein-Hitpaß, 2010). They bring their knowledge, skills and expertise back to the home country and contribute to its prosperity. Although much has been written about the brain drain, due to migration of the skilled and highly educated workforce away from its home country, the return of these innovators is characterised as brain gain as they are thought to contribute to their country of origin, and their return creates an educational and professional dividend in the home country (Batista et al., 2007).

\section{Return migration of Lithuanian home care workers}

This study examines the return of migrant home care workers to their home country, Lithuania. Worldwide, there is a growing reliance on migrant home care workers who provide care to older adults with physical and/or cognitive needs (England and Dyck, 2012). The reliance on migrant home care workers to provide care for older people is largely attributed to the low status assigned to the job and to the limited available informal carers to provide care to sick older adults (Anderson, 2007). To date, the exact number of Lithuanian migrant home care workers remains unclear. These workers migrate to countries such as Germany, Ireland, Spain or the United Kingdom.

Like the migration of professional workers, which has been characterised in terms of brain drain and brain gain, the migration of home care workers has been characterised within the care chain model (Lutz and Palenga-Möllenbeck, 2012). The care chain represents the interdependence between sending and receiving countries, which results in a flow of care workers from lower socio-economic countries to more affluent ones. This flow addresses the care drain in the receiving countries, which results in a care gain upon the migration of the workers to the receiving countries, but in a care drain in the sending countries (Yeates, 2012). 
In the case of Lithuania, as in other East European countries, this effect might be particularly pronounced due to its relatively high life expectancy, coupled by low childbirth, which suggest limited available family care-givers for older adults (Kasnauskiene and Vebraite, 2014). Whereas most care provided to older adults in Lithuania is informal in nature, provided by family members and friends, the formal long-term care system is primarily institutional and is highly disintegrated from the health-care system (Styczyńska, 2010; Poškute and Greve, 2017).

The return of migrant home care workers to their home country likely has its unique characteristics, which have not been explored to date (Ayalon, in press). In contrast to professional workers, migrant home care workers often experience precarious working conditions (van Bochove and zur Kleinsmiede, 2020). Their employment is unregulated and unsupervised, taking place behind closed doors (Ayalon, 2009a). Moreover, home care offers very limited opportunities for advancement on the job, either financially or professionally. As such, when specifically asked about their aspirations, home care workers do not want their children to work in the same occupation. They hope for a different future career for their children (Browne et al., 2006).

Home care and, in particular, migrant home care is not like any other job. Workers are expected to provide not only personal care but also emotional care (Bauer and Österle, 2013). Specifically, past research has shown that once a migrant worker enters the family, family members continue to serve as co-ordinators of care, but expect the migrant worker to perform in addition to personal care duties, also emotional care, becoming one of the 'family' (Ayalon, 2009b). As care is considered personal and private, and is seen as highly loaded with feelings and emotions, we tend to rarely consider it as work and, thus, fail to acknowledge its emotional toll on the carer (Hochschild, 1995).

The notion of emotional labour stems from the understanding and acknowledgement that to perform the job, one also must manoeuvre one's emotions and emotional responses. Hence, implicit and explicit rules concerning the display of emotions and emotional exchange are introduced. Under such circumstances, one might become estranged not only from one's expressed feelings, but also from one's internal emotional response to one's labour (Hochschild, 2012), in our case, the care and the care recipient. When it comes to the care of older people, ageism, manifested as stigma, prejudice and discrimination towards people because of their age (Ayalon and Tesch-Römer, 2018), might impact the care work and result in more-negative emotional response and less than optimal care provision (Liu et al., 2020).

In this context, this study is set to examine the reasons for return of migrant home care workers to Lithuania. Our focus is the accounts of migrant home care workers concerning the reasons for their return. As the reliance on migrant home care workers is highly common, worldwide, it is important to understand better the reasons behind the workers' return. The present analysis goes beyond a simplistic classification of success versus failure as reasons to return to one's home country. Instead, it aims to examine the possible disruption of the care chain, from the perspective of returning migrants. This information is relevant for policies in both sending and receiving countries. 


\section{Methods}

\section{Recruitment}

We recruited a diverse sample of participants who permanently returned home after providing care to older people abroad. We aimed to reach maximum variations in terms of the host country, number of years in the host country and number of years since the return to one's home country. The sample was recruited via personal networks (acquaintances of friends, colleagues, relatives of the interviewer), social media (groups on Facebook) and snowballing. Participants living in Vilnius were interviewed in person. Those living in other regions were interviewed by phone. The study was carried out in November and December 2019 .

The study was conducted in line with the fundamental ethical principles of anonymity, privacy and confidentiality, and in accordance with the ethical guidelines of the second author's research institution. Prior to participating in the study, all respondents gave their informed consent after receiving detailed information about the study. They were assured their information would be kept confidential and anonymous, and that they have the right not to answer questions and/or to quit the interview at any time.

\section{The sample}

A total of 12 women and one man were interviewed for this study. Interviewees worked as live-in home care workers. However, after several months abroad, one rented a flat so that she could spend the weekends on her own and one worked in a nursing home. Interviewees obtained their job abroad mainly via personal networks or through illegal agents. Their average age was 59, with the youngest being at the age of 39 and the oldest being 75 . Two worked in Italy, two in Germany and the remaining nine interviewees worked in the United States of America (USA). Time spent abroad ranged between 8 months and 17 years. The number of years since return varied dramatically between one month and 25 years. Nine respondents had university education (two had both university and professional education), three had only professional or higher non-university education and one had only secondary education. Their average years of education was roughly 16 . Table 1 outlines the characteristics of the sample.

\section{Procedure}

The interviewer was a Lithuanian sociologist (GR) with extensive experience in qualitative research. Each interview lasted between 40 minutes and one hour. All interviews were recorded and transcribed. Interviews started with a general question about the respondent's experience in the host country and reasons for migration. They also were asked about their relationships with other migrants, reasons for return to Lithuania, and care provided to children, grandchildren and parents (if relevant) while abroad and upon returning to Lithuania. Participants also were asked about their learning experiences while abroad and how lessons learned about care abroad possibly influence their care-giving experience in their home country. 
Table 1. Sample characteristics

\begin{tabular}{|c|c|}
\hline Characteristic & $\mathrm{N}$ \\
\hline \multicolumn{2}{|l|}{ Gender: } \\
\hline Women & 12 \\
\hline Men & 1 \\
\hline \multicolumn{2}{|l|}{ Age: } \\
\hline $39-50$ & 4 \\
\hline $51-62$ & 2 \\
\hline $63-74$ & 7 \\
\hline \multicolumn{2}{|l|}{ Education: $^{1}$} \\
\hline Secondary & 1 \\
\hline Professional & 4 \\
\hline University & 11 \\
\hline \multicolumn{2}{|l|}{ Nationality: } \\
\hline Lithuanian & 13 \\
\hline \multicolumn{2}{|l|}{ Family status: } \\
\hline Single & 3 \\
\hline Married & 5 \\
\hline Divorced & 2 \\
\hline Widow & 3 \\
\hline \multicolumn{2}{|l|}{ Country of work: } \\
\hline Germany & 2 \\
\hline Italy & 2 \\
\hline United States of America & 9 \\
\hline
\end{tabular}

Notes: $\mathrm{N}=13$. 1 . Two participants had both professional and university education. One participant had two university degrees.

\section{Analysis}

All interviews were read several times by GR who identified the main themes within each interview and subsequently across interviews. Initially, each interview was coded into small units of meaning. Next, codes were grouped into larger themes by grouping and regrouping codes to represent larger units of meaning (Miles et al., 2014). Finally, the two authors consulted to develop a coherent line of meaning, which portrays a logical plot. While doing so, we identified several major themes in the texts. These include paid versus unpaid care, reasons for migration, work conditions, family relationships and reasons for return migration.

\section{Findings}

In the present study, we decided to focus on reasons for return migration. While doing so, we attempted to identify the unique reasons proposed by home care 
workers, which take into account their distinct employment trajectories. Study participants provided various reasons for return, which we classified into three main sub-themes:

(1) Undocumented status was commonly mentioned as a reason for return. Because home care is an occupation which does not guarantee stability and often is unregulated, staying on the job in a different country was only a temporary choice for interviewees.

(2) Home care is mentally and physically taxing. As a result, the return home to pursue a different profession or to work as a home maker, caring for one's own children, grandchildren or parents, was seen as an appealing opportunity.

(3) The job increased awareness to possible losses. Specifically, working with older people and people with disability makes one realise that life is finite and that one's needs for care and support might increase with time.

In general, the interviewees stressed the nature of care work abroad as providing limited rewards and little stability, with minimal opportunities for advancement or settlement. The work was described as being highly demanding physically and emotionally. Care workers suffered emotionally and physically, and reported limited opportunities for developing a career, pursuing education or establishing family life. Co-experiencing the care recipient's challenges associated with old age and illness forces the care workers to think about their own family life and future care needs, and potentially to revise their value system and priorities. In the long run, financial gains were weighed against possible losses related to their own health, social integrity and identity. The care workers interviewed in this study had come to the difficult decision of 'enough' while weighing the benefits (financial) and the costs (physical, emotional, intellectual, social) of the work:

You see, everything comes with age already, as they say: God gave everything, only didn't give 'moderation'. And look, time comes on a beautiful day that you don't [want this], I say then, this is it. (11W71s-USA16 ${ }^{1}$ )

Thus, the return of care workers is driven by the wish to compensate for the nonfinancial costs associated with working abroad as a home care worker and to rebalance their lives.

\section{Illegal status: a source of insecurity}

The issue of legality was raised by several informants who migrated to the USA as a major reason for their return to their home country. A major problem related to the low status assigned to the job was the fact that informants illegally stayed or worked in the host country. This meant limitations on mobility, because any local trip involved the risk of deportation. The following is a quote from an interview with a 62-year-old woman who had spent 17 years in the USA:

Well, without this Green Card you can't make a move. You are scared every time, you know that later you would [not be] ... I was afraid of travel so as not to be deported. (9W62p-USA17) 
A study participant, who spent one year in the USA, also reported her extensive fears and concerns in the light of her undocumented status limiting her possibilities to know new people and develop her network:

When you are an illegal person, you, you are also afraid to tell somebody that you work illegally, because you never know, someone could report you and, God forbid. So, for example, the husband of that Juste [pseudonym] of mine was a big boss. Back then, if they helped a person to work illegally in America, they could have lost their own job, just gotten fired, so for me, making such trouble to a close friend and her family (smiles) seems ... So, look, you feel unsafe there just because of that. (7W68u-USA1)

The informants describe their illegal status as depressing. Reportedly, this has contributed to the fact that they remained strangers in the country, no matter how good their relationships with their employers. Moreover, they dared to trust only a few 'real friends':

There [in the USA], you still feel, no matter the love and everything, you still feel like a stranger there. (11W71s-USA16)

Other care workers returned home in order not to violate the visa restrictions:

Actually, the visa ran out, on top of all this, we did not want to violate that visa. (8W43u-USA1.25)

I had prolonged, you know, that residence permit, I wasn't there illegally ... and later, I already got that negative answer, you know, and I did not want at all to worsen very much my emigration history. (13W39u-USA1.25)

\section{The job is mentally and physically taxing}

If the first sub-theme represents the objective aspects associated with the job and the fact that many respondents, primarily those who immigrated to the USA, had to work under precarious working conditions with no official documentation and acknowledgement of their status, the second sub-theme represents the physical and emotional reactions to the job. Among the reasons mentioned by informants, fatigue was a very pronounced experience. Being on duty round the clock, a lack of sleep if the person cared for had serious health problems, and a lack of free time and rest time resulted in physical exhaustion. An interviewee said that he was exhausted due to a lack of sleep and wanted to leave after only several weeks abroad. The employers asked him to stay, improved his working conditions and gave him a day off. In addition, over time, he also started to take day naps, which he perceived as cheating. Still, the main reason for his return home after eight months in the USA was fatigue:

I could have stayed probably for another month, but I was also really exhausted, the old man had those strokes, and for me, well, I still felt really exhausted.

(6M41u-USA0.6) 
Even when the job was less demanding physically, participants revealed emotional tiredness. As another former student, who spent more than one year in the USA, put it:

...emotionally I couldn't really stay any longer, I don't know what would have happened to me if I had stayed, you know. It was very tough for me. I even had such a dream at the beginning that I would finish that job and I would travel. But when I finished all that, I did not want to travel anymore or anything, I just wanted to go home. (13W39u-USA1.25)

Fatigue also was described by another worman aged 68, who worked in Germany for 15 years. She reported being tired of adjusting to new household circumstances again and again:

Already at my own age, I was tired of those strange beds, those strange apartments, every time you have to get used to it coming to a new family, you have to get used to it, and to know where the dishes are, and what to eat, and those ovens and how to switch on, well everything, everything is new, so it got a bit ... a bit too difficult, every time a new, new, new and age and I said enough, that's it. I stayed for 15 years, I don't want it anymore. Although there were women over the age of 70 working with these old people, but I didn't want it, I was already losing my mind (laughs). From that boredom. (1W68p-DE15)

This interviewee is responding not to the physical challenges of the job, but to the emotional toll it has taken due to its under-stimulating nature.

Several study participants mentioned concrete threats to their mental wellbeing. Others have identified their deteriorated health as a reason to switch to a sedentary lifestyle after long years of international mobility. One woman, with no university education, who had spent 16 years working in the USA, was especially emotional about her decision to quit the job. For her, psychological fatigue was partially caused by efforts to overcome a lack of dignity experienced in several domains, including her working conditions, which had offered her limited freedom. She perceived herself being treated by her employers as a second-class human - perhaps also due to her minimal education. As she stated:

You see, the time comes that you, in a word, think that nobody needs you, you are anyhow a second- or third-class human and you have to fulfil, you see, each of his [patient's] caprice. If you are asleep, you have to listen with one ear at night if he is not coughing, if he is not getting up and walking. So, I say if you push through those five days, then those two days you relax, spend them and you come back again, and when, I say, it is time to go to work, the blood pressure starts to rise. Well, you see, you work, you live, but you live in captivity. It is not like you would live freely, you live in captivity. (11W71s-USA16)

She noticed how the margins of her patience were stretched and she could not work abroad anymore, as she could not 'control her nerves', i.e. her psychological resources were exhausted: 
such a psychological moment came that it was time to go home. That's all. Everything is plenty, everything is enough, I don't want anything, most importantly not to ... you have to, you work with people, you have to give them your heart. You have to look after him because he is old. And sometimes I see that, I think, I give everything and you, just sit there being whimsical. You see, and sometimes that and, and you think, well, why am I angry with them, they're old, they don't understand what they're doing, and if you can't already control your nerves and that's it, go home. (11W71s-USA16)

The high physical and psychological demands of the care work, coupled by limited educational resources, exacerbate the wish to return home. This has been augmented by disrespectful attitudes and a privacy breach reported by some of the respondents.

Informants have argued that the care work itself sometimes is very limited in terms of the ability to reach self-fulfilment. For instance, a highly educated informant (7W68u-USA1) admits that she would have wanted to have 'a job that is a bit of that higher level' or learning opportunities, that correspond with her university education. Being an older person herself, in Lithuania she had found more opportunities for education (like the University of the Third Age) and socialisation. Similarly, a former university student, who had spent eight months in the USA, explained his nostalgia to his home country. He reported missing the academic environment and the cultural life, which were inaccessible in the host country due to the isolating nature of the care work. Paradoxically, less-educated respondents did not express such needs.

Partial exceptions in this respect were reported when the care recipients were highly educated themselves. A woman, who worked for 12 years in Germany, was especially fascinated and thankful to a long-term care recipient who shared with her his culturally rich and pleasant lifestyle:

I ended up ... with such an amazing person and a famous person, to a doctor of medical sciences, a professor, a neurosurgeon ... Also, the more cultured the environment, the nicer are the relationships, because really, at that old woman's for me everyone was educated, and at the professor's, generally only doctors were there, high culture, and really, the respect is there and everything ... When I came to work at the professor's, he walked with a cane. We both visited a lot of concerts, performances, went to restaurants and cafes. Really, it was a lot of fun, very good. (2W72u-DE12)

A different account of a young woman, who had spent more than a year in the USA, also stressed the characteristics of the care recipient and the relationship with the care recipient as important factors. Reportedly, she was psychologically supported by her care recipient during emotionally difficult situations:

Well, she [care recipient] always supported me, you know. Well, in the sense that there was no such employee-employer relationship, it was such a very human connection ... There were, for instance, situations, well, I, for example, did not drive, at all. And there, to get that job with her, I had to get a [driver's] licence ... But 
then it would happen, I would be driving that Buick of hers, you know, and I had been, for example, driving dangerously, well, nonsense like that ... But even in such situations, she, you know, was always on my side... (13W39u-USA1.25)

To sum, our informants reported that especially in the case of live-in care, the relationship with the employer played a major role. However, for the most part, the possibilities for education or socialisation on the job were extremely limited. This, in addition to the unsecured nature of the job, the precarious working conditions and the fact that many workers were undocumented, contributed to the decision to return.

\section{The job increases awareness of possible personal losses}

Facing the reality of old age in a materially and culturally different environment has motivated informants to revise their own value system. Some informants, as an outcome of this painful process, reported an increase in the wish to live in their own country. The following woman, who had spent 17 years abroad, reported her broken hope to create a family of her own: 'I did not see the light at the end of the tunnel anymore, I am ageing, I am getting old, time to have something of your own' (9W62p-USA17).

Caring and actually living for others, as shaped by the live-in care situation, has forced informants to realise the emotional sacrifices they have made on the job:

Maybe enough of these old bags [care recipients] because soon those old bags will, because they ... they drain you completely, and what about me, who do you think will look after me? (11W71s-USA16)

This 71-year-old woman, who had spent 16 years in the USA, is concerned about her future care needs, and the reciprocity in her relationship, with the understanding that although she is caring for other older people, when she grows old there will be no one to take care of her. This extreme example was an incentive for her return home as she decided not to wait and move to her home country, while she was still alive:

You see, not to such an extent, no, you don't wait until you are brought back in a small box. So, I did not let it get out of hand that much, no, but you can really lose your mind there totally. (11W71s-USA16)

Some care workers returned to materialise their future plans, e.g. to continue their studies or to establish their own business. Others highlighted the importance of family relations in their lives and were strongly motivated to return to their family and children:

very much, well, very much the longing for the homeland and the love for my old dad. (7W68u-USA1)

Similarly, a 51-year-old woman stated: 'If it were not for my children and husband or my parents, I would not have been back' (12W51u-USA2). 
Some informants revealed that the familiar cultural environment was also of importance. This meant wishing to move to Lithuania even for a short period or describing one's home country as a comfort zone. This is expressed in a report of a woman who worked in the USA during her university studies:

Well, maybe I'll have an apartment here [in the home country], a husband, children, well, something, I'll get lucky at least a bit. But I also saw some not very successful stories there [abroad]. (8W43u-USA1.25)

These diverse perspectives point to the fact that future lost opportunities were seen differently by the different respondents based on their position along the lifecourse. Whereas older migrant care workers were concerned about their future care needs, younger workers reported a concern about the weakening emotional family bonds or the limited opportunities for developing intimate relationships.

\section{Discussion}

The present study evaluated reasons for return to one's home country, Lithuania, after working as a home care worker abroad. The study is unique because it highlights the relationship between the type of job one performs abroad, the employment characteristics in the particular host country and one's reasons for return. Worldwide, migrant home care workers provide care to older adults in more affluent regions and countries (Fudge, 2012). Although much has been written about this care-giving arrangement in the receiving countries, the perspective of those who have returned to their sending countries remains limited. This study contributes to our understanding of the disruption of the care chain by adding information about the unique reasons that push home care workers away from their host country back to their home country.

Our findings suggest that focusing on home care workers as a unique population that has its own struggles and assets is informative and provides a realistic portrayal of their reasons for returning home, which go beyond a simple classification of success versus failure. Our findings clearly show that the precarious working conditions of the job are a major reason for return. Specifically, home care occurs behind closed doors. It is often unsupervised as it represents a personal arrangement that occurs between an older adult, his or her family members, and a care worker (Ayalon, 2009b; Ayalon and Green, 2015). Under this arrangement, many irregularities and even abuse can take place. Whereas in order to work in a hospital or a nursing home as a care worker, one needs legal documents, this is not always needed when working at home (Raijman et al., 2003). This may result in highly precarious working conditions that push the worker back to his or her home country.

Of the 13 interviewees, nine immigrated to the USA. In contrast to Europe, which allows Lithuanians to work on equal terms as EU citizens, the USA has no such work agreements with Lithuania. As such, a main argument for leaving one's job as a home care worker in the USA was the undocumented status of the job. This was not the case for those returning migrants who worked in Europe. The findings clearly stress the importance of obtaining legal status for the ability of the worker to stay in the host country. The findings are explained by the high 
levels of emotional distress found among undocumented migrants in past research (Myhrvold and Småstuen, 2017).

The issue of documentation was not the only one raised by the workers interviewed in this study, most of whom used to work as live-in workers, thus having very limited opportunities to socialise, learn or self-develop. The workers reported very intense working conditions that allowed no time for oneself. The routine work of care was described as boring and exhausting, and workers reported feelings of burnout and burden as a result. Such feelings are common among both paid and unpaid carers (Ayalon and Green, 2015). Our findings stress that these feelings might serve as precipitators of the decision to move to one's home country.

The provision of care to older people behind closed doors is not only a physically taxing job, but also an emotional one (Ayalon, 2009b). Although some workers reported very satisfying and enriching relationships with their care recipients, others reported being intensely monitored, having limited time to themselves. Hence, it is not only the physical strain or lack of sleep, but also one's emotional capacity and freedom that are being compromised, as reported in past research (Green and Ayalon, 2018).

It also is important to acknowledge the fact that in the present study care was provided to older people. Thus, stereotypes of older people might play a role in the wish to perform the job (Shinan-Altman et al., 2020) and eventually return to one's home country. Viewing older care recipients as 'old bags', as mentioned by the least educated respondent, certainly does not add much appeal to the job and might make the emotional work even harder (Hochschild, 2012).

Another interesting finding concerns the fact that the job itself has raised informants' concerns about their own mortality and care needs. Caring for others has raised questions about their own available care network and the people whom they care for and who may care for them one day. This highlights the similarities between paid and unpaid care work (Ayalon and Green, 2015). Although informants were hired to provide personal care and assist older people with their activities of daily living, their experiences were highly emotional and their understanding of the consequences of migration also were partially led by emotional rather than intellectual reasoning. Moreover, the positive experiences workers had on the job also were emotional in nature. Similar to past research (Ayalon and Roziner, 2016), which has stressed the important role of the relationships between paid carers and their care recipient, the present study has identified this interconnection as an important factor of high impact on care workers' mental wellbeing.

In reviewing the findings, it is important to note that although we attempted to obtain a diverse sample, our sample consisted mainly of women who returned to Lithuania from the USA. As noted above, those who returned from Europe likely had somewhat different experiences, given the geographic and cultural proximity, and their legal status. It also is possible that men experience their work as home care workers differently. It is women who are more likely to provide care, but less likely to receive such care in old age (Greenberg and Ginn, 1979; Patterson and Margolis, 2019). Moreover, it is migrant women who might be criticised for deserting their family of origin, whereas migrant men are exempt from such criticism (Gibson et al., 2001). Therefore, interviewees' concerns about the type of relationship and care they will receive upon their return likely are fuelled by these 
global gendered experiences. Although the highly gendered nature of care work, which relies heavily on women, is not surprising (Gammage and Stevanovic, 2019), future research will benefit from exploring reasons for return in a more diverse sample. The fact that our sample included a single male prevents us from acknowledging fully the intersection between gender and migration status. It also is important to note that most interviewees were highly educated. This is typical of migrants, who tend to be highly educated, yet, pursue positions abroad for which they often are overqualified (Nowotny, 2016). This likely impacts their experiences abroad as well as their decision to return home.

\section{Conclusions}

Our findings move away from a dichotomous classification of return migration as failure versus success by pointing out the unique characteristics of this occupation as a push factor, away from the host country back to one's home country. In addition to here-and-now challenges on the job, such as the undocumented nature of the job when performed in non-European countries, and the physical and emotionally demanding characteristics of care work, especially when provided round the clock (Ayalon, 2009b), our findings also point to the future-oriented aspirations and concerns of migrant care workers. Workers' concerns about their future varied somewhat based on their placement along the lifecourse trajectories and their personal and social resources. Whereas older workers were more likely to worry about their future care needs, younger workers worried about relational issues. This information is important considering the global reliance on migrant care (Lutz and Palenga-Möllenbeck, 2012). Although home care occurs behind closed doors, it is highly important to ensure that this care arrangement is well supervised and that a working permit is in place. Our findings stress the fact that an undocumented working status hurts the worker and poses a major stressor and a precipitator for the return to one's home country. Our findings also show that the migrant workers, like all other human beings, need time of their own to develop, explore, learn and socialise. Hence, precarious working conditions impact not only the workers, but also the care chain, which is disrupted in the long run. Moreover, migrant workers did not invest only in the present, but also in the future, with the care work for older adults serving as a constant reminder of their future care needs and availability.

\section{Policy implications}

When considering the findings from a policy standpoint, a first question that comes to mind is whether the host country even wishes the worker to stay. This is not a trivial question as in some countries, such as Israel or Singapore for instance, the migrant home care worker is expected to work for a limited period and move back to his or her home country afterwards. Nonetheless, even these countries wish the workers to be satisfied and content with their work. Another issue stressed by the present findings is the fact that it is not only the challenges faced by the current working conditions and the emotional and physcial demands put on the worker, but also his or her future time perspective. The migrant home care workers 
interviewed for this study lacked a perceived future as home care workers for older people. As such, our findings point to the need to prepare and train the worker not only to perform his or her daily work, but also to prepare for a future. Moreover, the present findings, similar to past research (Ayalon, 2009a), show that the worker needs time for themselves and cannot be fully invested in care, if care is to be provided adequately. The workers' attitudes towards older people and care work also must be addressed to ensure satisfactory relationship and care work.

\section{Note}

1 All informants were given codes: numerals $1-13=$ the serial number of the interview; gender ( $\mathrm{W}=$ women, $\mathrm{M}=$ men); age of the informant; education ( $\mathrm{s}$ = secondary, $\mathrm{p}=$ professional or no-university, $\mathrm{u}=$ university); work country ( $\mathrm{DE}=$ Germany) and years worked there.

\section{References}

Anderson B (2007) A very private business: exploring the demand for migrant domestic workers. European Journal of Women's Studies 14, 247-264.

Ayalon L (2009a) Evaluating the working conditions and exposure to abuse of Filipino home care workers in Israel: characteristics and clinical correlates. International Psychogeriatrics 21, 40-49.

Ayalon L (2009b) Family and family-like interactions in households with round-the-clock paid foreign carers in Israel. Ageing \& Society 29, 671-686.

Ayalon L (in press) The global care network and its impact on sending and receiving countries: current knowledge and future directions. Ageing \& Society. Available online doi:10.1017/S0144686X21000027.

Ayalon L and Green $\mathbf{O}$ (2015) Live-in versus live-out home care in Israel: satisfaction with services and caregivers' outcomes. The Gerontologist 55, 628-642.

Ayalon L and Roziner I (2016) Satisfaction with the relationship from the perspectives of family caregivers, older adults and their home care workers. Aging \& Mental Health 20, 56-64.

Ayalon L and Tesch-Römer C (2018) Contemporary Perspectives on Ageism. Berlin: Springer.

Barcevičius E (2016) How successful are highly qualified return migrants in the Lithuanian labour market? International Migration 54, 35-47.

Bastia T (2011) Should I stay or should I go? Return migration in times of crises. Journal of International Development 23, 583-595.

Batista C, Lacuesta A and Vicente PC (2007) Brain drain or brain gain? Micro evidence from an African success story. Institute for the Study of Labor, Bonn, Germany, IZA Discussion Paper 5048. Available at https://www.iza.org/publications/dp/3035/brain-drain-or-brain-gain-micro-evidence-from-an-african-successstory.

Bauer G and Österle A (2013) Migrant care labour: the commodification and redistribution of care and emotional work. Social Policy and Society 12, 461-473. doi:10.1017/S1474746413000079.

Birka (2019) Can Return Migration Revitalize the Baltics? Estonia, Latvia, and Lithuania Engage Their Diasporas, with Mixed Results. Migration Information Source. Accessed online on November, 2021: https://www.migrationpolicy.org/article/can-return-migration-revitalizebaltics- estonia-latvia-and-lithuania-engage-their-diasporas.

Browne CV, Braun KL and Arnsberger P (2006) Filipinas as residential long-term care providers: influence of cultural values, structural inequity, and immigrant status on choosing this work. Journal of Gerontological Social Work 48, 439-455.

Cela E (2017) Migration and return migration in later life to Albania. In King R and Vathi Z (eds), Return Migration and Psychosocial Wellbeing: Discourses, Policy-making and Outcomes for Migrants and Their Families. Abingdon, UK: Routledge, pp. 203-220.

England K and Dyck I (2012) Migrant workers in home care: routes, responsibilities, and respect. Annals of the Association of American Geographers 102, 1076-1083.

Fudge J (2012) Global care chains: transnational migrant care workers. International Journal of Comparative Labour Law \& Industrial Relations 28, 63-69. https://kluwerlawonline.com/journalarticle/International+Journal+of+Comparative+Labour+Law+and+Industrial+Relations/28.1/IJCL2012005. 
Gammage S and Stevanovic N (2019) Gender, migration and care deficits: what role for the sustainable development goals? Journal of Ethnic and Migration Studies 45, 2600-2620.

Gibson K, Law L and McKay D (2001) Beyond heroes and victims: Filipina contract migrants, economic activism and class transformations. International Feminist Journal of Politics 3, 365-386.

Girma H (2017) The salience of gender in return migration. Sociology Compass 11, e12481.

Green $\mathbf{O}$ and Ayalon L (2018) Violations of workers' rights and exposure to work-related abuse of live-in migrant and live-out local home care workers - a preliminary study: implications for health policy and practice. Israel Journal of Health Policy Research 7, 32.

Greenberg JN and Ginn A (1979) A multivariate analysis of the predictors of long-term care placement. Home Health Care Services Quarterly 1, 75-99.

Hagan JM and Thomas Wassink J (2020) Return migration around the world: an integrated agenda for future research. Annual Review of Sociology 46, 533-552.

Hochschild AR (1995) The culture of politics: traditional, postmodern, cold-modern, and warm-modern ideals of care. Social Politics: International Studies in Gender, State \& Society 2, 331-346.

Hochschild AR (2012) The Managed Heart: Commercialization of Human Feeling. Berkeley, CA: University of California Press.

Kasnauskiene G and Vebraite L (2014) The impact of migration on Lithuanian economy in an ageing society context. International Journal of Business and Management 2, 31-42.

Klagge B and Klein-Hitpaß K (2010) High-skilled return migration and knowledge-based development in Poland. European Planning Studies 18, 1631-1651.

Klinthäll M (2006) Retirement return migration from Sweden. International Migration 44, 153-180.

Kofman E (2013) Gendered labour migrations in Europe and emblematic migratory figures. Journal of Ethnic and Migration Studies 39, 579-600.

Labanauskas L (2019) Highly skilled migration from Lithuania: a critical overview of the period 1990-2018. Sosyoloji Dergisi/Journal of Sociology 39, 229-248.

Liu C-C, Liu L-F and Chuang S-S (2020) The effect of ageist behaviors on home care workers' job satisfaction and retention in long-term care. Journal of Applied Gerontology 8, 733464820975598. doi: 10.1177/0733464820975598. Epub ahead of print. PMID: 33292035.

Lutz H and Palenga-Möllenbeck E (2012) Care workers, care drain, and care chains: reflections on care, migration, and citizenship. Social Politics 19, 15-37.

Miles MB, Huberman AM and Saldana J (2014) Qualitative Data Analysis: A Methods Sourcebook. Thousand Oaks, CA: Sage.

Myhrvold T and Småstuen MC (2017) The mental healthcare needs of undocumented migrants: an exploratory analysis of psychological distress and living conditions among undocumented migrants in Norway. Journal of Clinical Nursing 26, 825-839.

Nowotny K (2016) Are overqualified migrants self-selected? Evidence from central and Eastern European countries. Journal of Human Capital 10, 303-346.

Olesen H (2002) Migration, return, and development: an institutional perspective. International Migration 40, 125-150.

Patterson SE and Margolis R (2019) The demography of multigenerational caregiving: a critical aspect of the gendered life course. Socius 5. Available at https://doi.org/10.1177/2378023119862737.

Poškutė V and Greve B (2017) Long-term care in Denmark and Lithuania - a most dissimilar case. Social Policy \& Administration 51, 659-675.

Preston K and Grimes A (2019) Migration, gender, wages and wellbeing: who gains and in which ways? Social Indicators Research 144, 1415-1452.

Raijman R, Schammah-Gesser S and Kemp A (2003) International migration, domestic work, and care work: Undocumented Latina migrants in Israel. Gender \& Society 17, 727-749.

Shinan-Altman S, Soskolne V and Ayalon L (2020) Becoming a home care worker: job-seekers' push and pull factors. Research on Aging 42, 62-71.

Sipavičienè A and Stankūnienè V (2013) The social and economic impact of emigration on Lithuania, in OECD (2013). In Coping with Emigration in Baltic and East European Countries, OECD Publishing, pp. 65-110. https://doi.org/10.1787/9789264204928-6-en.

Stoller EP and Longino Jr CF (2001) 'Going home' or 'leaving home'? The impact of person and place ties on anticipated counterstream migration. The Gerontologist 41, 96-102. 
Styczyńska I (2010) The Lithuanian Long-term Care System (CASE Network Studies \& Analyses No. 414/ 2010). Available at https://papers.ssrn.com/sol3/papers.cfm?abstract_id=1710612.

Thaut L (2009) EU integration \& emigration consequences: the case of Lithuania. International Migration 47, 191-233.

United Nations International Organization for Migration (2011) Migration Profile: Lithuania. International Organization for Migration Mission in Lithuania. Available at https://www.iom.int/countries/lithuania.

United Nations International Organization for Migration (2020) World Migration Report 2020. Available at https://publications.iom.int/system/files/pdf/wmr_2020.pdf.

van Bochove M and zur Kleinsmiede D (2020) Broadening the scope of live-in migrant care research: how care networks shape the experience of precarious work. Health \& Social Care in the Community 28, $51-59$.

Wang WW and Fan CC (2006) Success or failure: selectivity and reasons of return migration in Sichuan and Anhui, China. Environment and Planning A 38, 939-958.

Yeates N (2012) Global care chains: a state-of-the-art review and future directions in care transnationalization research. Global Networks 12, 135-154.

Zaiceva A and Zimmermann KF (2016) Returning home at times of trouble? Return migration of EU enlargement migrants during the crisis. In Kahanec M and Zimmermann KF (eds), Labor Migration, EU Enlargement, and the Great Recession. Berlin: Springer, pp. 397-418.

Cite this article: Ayalon L, Rapoliene G (2021). The disruption of the care chain: why do Lithuanian migrant home care workers return to their home country? Ageing \& Society 1-17. https://doi.org/ $10.1017 / \mathrm{S} 0144686 \mathrm{X} 21001562$ 